\title{
Effects of differently cushioned running shoes at left and right foot on running symmetry
}

\author{
Torsten Brauner $^{1 *}$, Thorsten Sterzing ${ }^{2}$, Mathias Wulf ${ }^{1}$, Thomas Horstmann ${ }^{1,3}$ \\ From 4th Congress of the International Foot and Ankle Biomechanics (i-FAB) Community \\ Busan, Korea. 8-11 April 2014
}

\section{Background}

The cushioning of running shoes and leg stiffness influence tibial impact shock [1]. This knowledge, however, is based on investigations with the same cushioning at both feet. Unknown is whether leg stiffness can be adjusted for each leg individually. Thus, the purpose of this study was to quantify effects of differently cushioned running shoes at the left and right foot on running symmetry.

\section{Methods}

Twenty-eighty physically active males $(26.8 \pm 8.4$ years, $1.80 \pm 0.05 \mathrm{~m}, 74.8 \pm 7.5 \mathrm{~kg}$ ), with similar left and right leg stiffness, participated in this study. Two pairs of identical custom-made running shoes, representing hardercushioned (mechanical impact testing at rearfoot: $13.8 \mathrm{~g}$ ) and softer-cushioned (10.2g) footwear, were used. The four single shoes were combined into four experimental conditions (left foot-right foot): hard-hard, hard-soft, soft-hard, soft-soft). In each condition, subjects ran $200 \mathrm{~m}$ on a concrete track at self-selected pace. Conditions were blinded, the order randomized and a $100 \mathrm{~m}$ run was performed in a neutral running shoe between conditions. Directly following each condition, subjects rated the cushioning of the left and right shoe separately on a visual analogue scale $(0 \mathrm{~cm}=\mathrm{soft}, 10 \mathrm{~cm}=$ hard $)$. A mobile 3D accelerometer (Humotion, Germany) strapped to the lower back at L5-S1 recorded vertical acceleration. As a measure of running symmetry [2], peak vertical impacts of 32 foot-falls were determined for each leg. Left and right impact peaks and subjective cushioning ratings were compared using paired Student T-Tests $(\alpha=.05)$.

\section{Results}

In both of the mixed conditions, subjects perceived the soft shoe to be significantly softer than the hard shoe ( $\mathrm{p}=.031)$, according to their actual mechanical impact hardness. Vertical impact peaks at the lower back did not differ between any of the tested conditions and were symmetrical for the mixed conditions.

\section{Discussion}

Despite the well described effects of shoe cushioning on tibial impact shock, impact at the lower back was not influenced by differently cushioned running shoes. Thus, runners adapted their ankle, knee and/or hip stiffness, reducing the impact shock on its way upward. Interestingly, as runners perceived different cushioning of shoes correctly, this adaptation was controlled for each leg

Table 1 Vertical impact at lower back and VAS rating of cushioning perception

\begin{tabular}{|c|c|c|c|c|c|c|c|c|}
\hline & Left hard & Right soft & Left soft & Right hard & Left hard & Right hard & Left soft & Right soft \\
\hline Impact [g] & $\begin{array}{c}1.97 \\
(0.50)\end{array}$ & $\begin{array}{c}2.01 \\
(0.47)\end{array}$ & $\begin{array}{c}2.01 \\
(0.54)\end{array}$ & $\begin{array}{c}2.01 \\
(0.49)\end{array}$ & $\begin{array}{c}2.01 \\
(0.55)\end{array}$ & $\begin{array}{c}2.02 \\
(0.48)\end{array}$ & $\begin{array}{c}2.00 \\
(0.52)\end{array}$ & $\begin{array}{c}2.02 \\
(0.47)\end{array}$ \\
\hline Rating [VAS 0-10] & $\begin{array}{c}5.1 \\
(2.5)\end{array}$ & $\begin{array}{c}4.1 \\
(2.2)\end{array}$ & $\begin{array}{c}4.3 \\
(1.9)\end{array}$ & $\begin{array}{c}5.0 \\
(2.1)\end{array}$ & $\begin{array}{c}5.2 \\
(2.3)\end{array}$ & $\begin{array}{c}5.2 \\
(2.3)\end{array}$ & $\begin{array}{c}4.6 \\
(2.2)\end{array}$ & $\begin{array}{c}4.7 \\
(2.2)\end{array}$ \\
\hline
\end{tabular}

* Correspondence: torsten.brauner@tum.de

${ }^{1}$ Technische Universität München, Munich 80992, Germany 
individually, so that also in the mixed cushioning conditions the shock at the lower back remained symmetrical.

\section{Conclusion}

Maintaining low and symmetrical impacts at the lower back seems to be important during running, and is achieved by adjusting the leg stiffness, which can even be controlled for each leg individually. In further research, the mechanism of this individual leg stiffness control should be investigated.

\section{Acknowledgement}

We thank the Li Ning Sports Science Research Center for funding this research.

\section{Authors' details}

${ }^{1}$ Technische Universität München, Munich 80992, Germany. ${ }^{2}$ Sports Science Research Center, Li Ning (China) Sports Goods Co Ltd, Beijing 101111, China. ${ }^{3}$ Medicalpark St. Hubertus, Bad Wiessee 83707, Germany.

Published: 8 April 2014

\section{References}

1. Potthast $W$, Brüggemann $G$, Lundberg $A$, Arndt $A$ : The influences of impact interface, muscle activity, and knee angle on impact forces and tibial and femoral accelerations occurring after external impacts. J Appl Biomech 2010, 26(1):1-9.

2. Moe-Nilssen R, Helbostad JL: Estimation of gait cycle characteristics by trunk accelerometry. J Biomech 2004, 37(1):121-6.

doi:10.1186/1757-1146-7-S1-A8

Cite this article as: Brauner et al:: Effects of differently cushioned running shoes at left and right foot on running symmetry. Journal of Foot and Ankle Research 2014 7(Suppl 1):A8.

\section{Submit your next manuscript to BioMed Central} and take full advantage of:

- Convenient online submission

- Thorough peer review

- No space constraints or color figure charges

- Immediate publication on acceptance

- Inclusion in PubMed, CAS, Scopus and Google Scholar

- Research which is freely available for redistribution

Submit your manuscript at www.biomedcentral.com/submit 